\title{
Publipostage FMH Services «Achats groupés»
}

\section{Félicitations aux gagnants!}

Nous sommes heureux de pouvoir vous communiquer les noms des gagnants du tirage au sort du publipostage sur les achats groupés de mars 2007.

\section{$1^{\text {er }}$ prix}

Séjour de 2 nuits pour deux personnes dans une suite junior avec un riche buffet de petit déjeuner et accès libre au club wellness Sassa de l'Hôtel Villa Sassa \& Spa ${ }^{\star \star * *}$ à Lugano. Ce prix est offert par l’Hôtel Villa Sassa \& Spa ${ }^{\star * * *}$.

La gagnante est Mme le Dr Sabine Werner de St-Moritz (à gauche). Sandra Stadelmann de FMH Consulting Services (à droite) a remis le prix à l'heureuse élue.

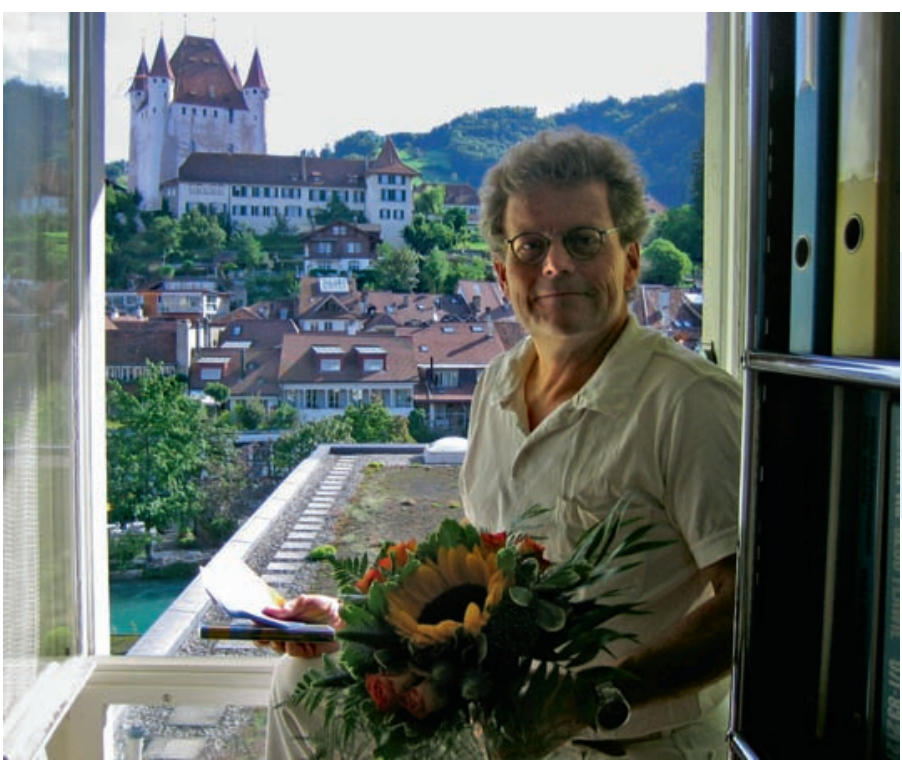

\section{$3^{\mathrm{e}}$ prix}

Machine à café Nespresso SIEMENS SN30 de l'entreprise Uneltech Electronic SA.

Claudine Tannari de FMH Consulting Services (à droite) remet le prix à Monsieur le Dr Martin Stiefel d'Uster (à gauche).

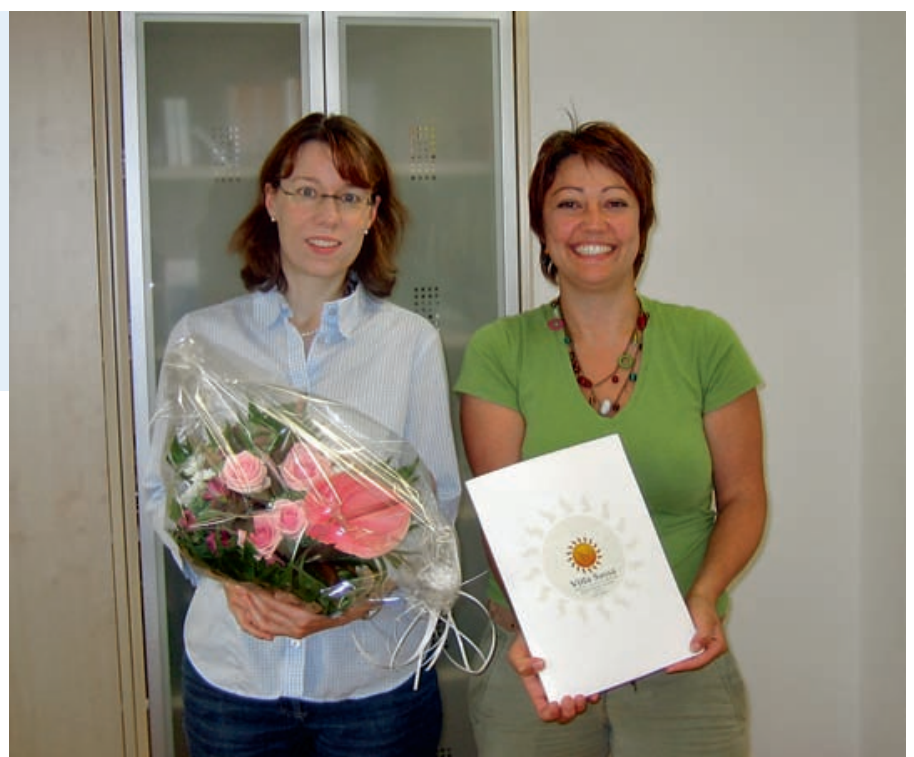

\section{$2^{\mathrm{e}}$ prix}

Chèques Reka d'une valeur de Fr. 500.- ainsi qu'un livre sur les randonnées dans le Toggenburg édité par l'entreprise P. Schmid \& Co. SA.

Le gagnant est Monsieur le Dr Jean-Jacques Loertscher de Thoune.

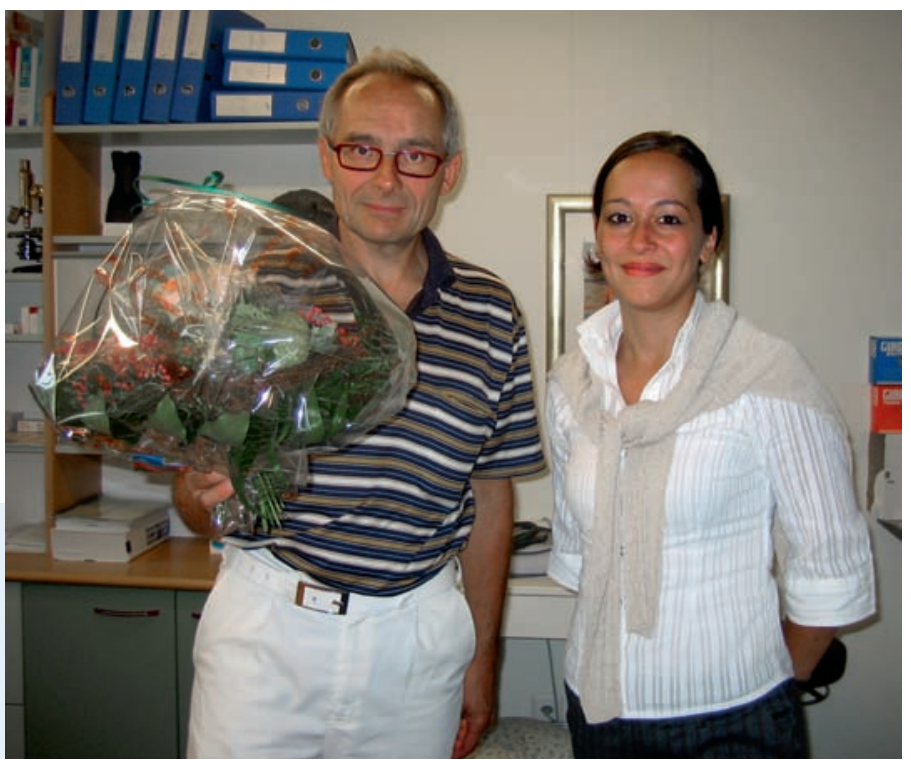


Vous souhaitez effectuer vos achats en profitant du système d'achats groupés de FMH Consulting Services? Au cours de la première année, les nouveaux clients peuvent profiter d'un rabais de $2 \%$ sur tous les achats auprès de nos fournisseurs agréés.

\section{Vos avantages}

- Une seule facture mensuelle pour tous les achats effectués auprès de nos fournisseurs agréés pendant les 4 à 6 semaines précédentes;

- la charge administrative se limite à un paiement;

- les frais bancaires sont réduits;

- des fournisseurs agréés triés sur le volet garantissent des prestations de premier ordre à des conditions avantageuses.

\section{Marche à suivre}

- Vous établissez votre commande directement à l'intention de nos fournisseurs;

- ces derniers envoient la facture mensuelle à FMH Consulting Services;

- nous réglons la facture le 20 du mois qui suit;

- vous recevez une facture groupée le 15 de chaque mois.

\section{Talon-réponse}

J Je souhaite effectuer mes achats auprès des fournisseurs suivants et profiter du système de factures groupées. J'ai pris connaissance du fait que cette prestation de FMH Consulting Services est gratuite.

Aichele Medico SA, Bâle

Apotheke zum Mörser, Zurich

Dr F. Rappai, Schlieren

Dr Grossmann, Birsfelden

Galexis SA, Schönbühl

IVF, Neuhausen

Medicare SA, Zurich

Medpro Novamed SA, Flawil

O Mepha Pharma SA, Aesch
Polymed Medical Center, Glattbrugg

Raetus-Apotheke, Coire

Rufma SA, Bremgarten

Salzmann AG, St-Gall

Spirig SA, Egerkingen

Spiromed, Gelterkinden

Streuli \& Co. SA, Uznach

Uneltech Electronic SA, Schwerzenbach

Unitobler Apotheke, Berne

Nom / prénom

Adresse

NPA / localité

Tél. privé

Tél. professionnel

Numéro concordataire

Courriel

Lieu / date / signature

\section{FMH CONSULTING}

